\title{
What Does Teaching and Learning Look like in a Variety of Classroom Spatial Environments?
}

\author{
Terry Byers
}

\begin{abstract}
The very nature of what constitutes an effective learning environment is undergoing substantial re-imagination. Authors have suggested that the affordances of existing learning spaces, often termed conventional or traditional classrooms, is limited and constrains the possible pedagogies available to teachers. Architects, authors and governments have put forward innovative learning environments (ILEs) as a better alternative. ILEs provide affordances thought to be somewhat better at providing to students learning needs than traditional classrooms, particularly in terms of creative and critical thinking, and collaborative and communicative workers. However, there is little evidence available to show of either spatial type (traditional classroom or ILE) performs pedagogically to either hinder or support the desired approach/es to teaching and learning being sought by current educational policies. One could suggest that a populistic narrative often drives the growing investment in new school learning spaces, facilitated by a vacuum of credible evidence of their impact. This paper will report findings from a three-year study that tracked the practices over time of secondary school Engineering, Mathematics and Science teachers $(n=23)$ as they occupied two quite dissimilar spatial layouts. The Linking Pedagogy, Technology, and Space (LPTS) observational metric, with its provision of instantaneous quantitative visual analysis, was used to track their practice, and student learning, in a variety of spatial layouts. Subsequent analysis identified broad trends within the data to identify those factors, spatial, subject or confounding teacher factors, which influenced student and teacher activities and behaviours. Importantly, it presented new evidence that works against the current, overt focus on contemporary spatial design. It suggests that greater emphasis on unpacking, and then developing, the mediating influence of teacher spatial competency (how, when and why one uses the given affordances of space for pedagogical gain) is required for any space to performance pedagogically.
\end{abstract}

\footnotetext{
T. Byers $(\varangle)$

The Anglican Church Grammar School, Brisbane, Australia

e-mail: Terry.Byers@ churchie.com.au
}

The University of Melbourne, Melbourne, Australia

W. Imms and T. Kvan (eds.), Teacher Transition into Innovative Learning Environments, https://doi.org/10.1007/978-981-15-7497-9_16 


\section{Introduction}

The critical drivers of digital technology, neoliberal policy and the subsequent drive for quality teaching and learning, have led some to question the efficacy of conventional or traditional classrooms (Benade, 2016; Dovey \& Fisher, 2014). Such a reconsideration stems from the emergent view that their 'built pedagogy' (Monahan, 2002) is somewhat constrained and favours more teacher-led and didactic instruction (Fisher, 2006; Tanner, 2008; Upitis, 2004). Dovey and Fisher (2014) surmise that this inhibits the ability of teachers to enact a broader spectrum of pedagogies as dictated by policies, which favour a higher incidence of student-centric and technology-enhanced learning.

This appraisal of existing designs has led to experimentation with more contemporary spatial models, often referred to as innovative learning environments (ILEs). The Organisation for Economic Cooperation and Development (OECD) describe ILEs as multi-modal, technology-infused and flexible learning spaces that are responsive to evolving educational practices (OECD, 2013). ILEs intend to provide those affordances and support a view of learning that is thought to be somewhat better than a traditional classroom (Benade, 2016). However, recent reviews found few evaluative approaches (Painter et al., 2013), hence little empirical evidence (Blackmore, Bateman, O'Mara, \& Loughlin, 2011), that indicates how ILEs, or in fact traditional classrooms, perform pedagogically (Byers, Imms, Mahat, Liu, \& Knock, 2018; Gislason, 2010).

A three-year-longitudinal observational study followed teachers in their occupation of different spatial layouts in a secondary school-in Australia this comprises students from approximately 13-18 years of age. This paper will report on a comparative analysis of teachers $(n=23)$ from the 'conceptually similar' subjects of Engineering, Mathematics and Science. Repeated measures obtained using the Linking Pedagogy, Technology, and Space (LPTS) observational metric (Byers, 2017), presented quantitative data in the form of 'timed' student and teacher activity and behaviour. Subsequent visual analysis evaluated those factors, spatial or other, that could be interpreted as influencing the pedagogical performance of the differing learning environment being used by these teachers over time. Importantly, this study illuminated how teachers from the same subject areas taught in a range of spatial environments. It identified the previously theorised concept of spatial competency (by Lackney, 2008; Leighton, 2017; Steele, 1973) to explain how teachers worked with and used (or not) the various affordances of the given learning environment for pedagogical gain; or indeed if they were agonistic in their use.

\section{The Study}

This longitudinal study of Engineering, Mathematics and Science teachers and their students took place in an independent (private) secondary school in the state of Queensland, Australia. It explored the belief that different spaces are 'agents for 
change' that lead to changed practice (Oblinger, 2006). As Mulcahy, Cleveland, and Aberton (2015) suggested 'how [and if] these changes take effect ... remains an open question [with] little educational research' existing on the impact of traditional or ILEs (p. 576). Such a statement is concerning, given the growing financial and human investment in school learning spaces. It is argued that contemporary learning narratives (such as the current twenty-first-century learning or skills discourse) and personal ideologies (architectural, academic and school leader) underpin the interest and investment in school spaces; despite the lack of empirical evidence articulating their pedagogical value. Many (Brooks, 2011; Byers, Imms, Mahat, et al., 2018; Painter et al., 2013) lament a lack of rigorous methodologies and methods capable of isolating the impact of different spaces on teaching and learning, while accounting for the spuriousness effect/s of the confounding variables at play in the educational setting.

To evaluate the impact of different spatial layouts, ascertained by the typology established by Dovey and Fisher (2014), what was of interest to this study was:

(1) How do different spatial layouts affect teacher behaviour and the pedagogies they employed?

(2) How do the various spatial types affect students' learning experiences?

- Earlier quasi-experimental studies at this site (see Byers, Hartnell-Young, \& Imms, 2018; Byers \& Imms, 2014, 2016; Byers, Imms, \& Hartnell-Young, 2014, 2018a, 2018b; Imms \& Byers, 2016) explored the impact of traditional classroom layouts and ILEs on teaching and learning. Findings linked the occupation of different spaces with statistically significant changes in student perceptions in the utilisation of technology, the incidence of more active and responsive learning experiences, and enhanced behavioural and cognitive engagement. The transition from traditional classrooms to spaces, encapsulating the intent of an ILE, noted changes to pedagogies and student engagement that were correlated with 'medium' within-group hedges $(g)$ effect size (due to a class as the unit of analysis) calculations (see Table 1). Furthermore, these iterative studies yielded similar Hierarchical Linear Modelling (HLM) findings of Tanner (2008). The HLM in various studies returned an averaged $7 \%$ variance in achievement attributed to the different learning environments (while controlling the confounding variables of student IQ, class composition and the teacher).

Even though these studies presented quantitative data that described to some degree the impact of different spaces on student learning, they also highlighted the importance of the mediating influence of teachers' spatial competencies (Lackney, 2008; Leighton, 2017). These studies identified a general correlation in enhanced learning experiences and engagement that led to higher academic results, but the relationship was not causal. These quasi-experimental studies were not able to discern or isolate the underlying, or micro, changes that affected their impact. Some teachers 
Table 1 Summary of within-group effect size $(g)$ calculations evaluating the pre- and post-spatial intervention on academic achievement across multiple studies

\begin{tabular}{l|l|l|l|l}
\hline Subject & Number of studies & Study design & $\begin{array}{l}\text { School year } \\
\text { (age range })\end{array}$ & Effect size $(g)$ value \\
\hline English & 2 & A/B* & $\begin{array}{l}7-9 \\
(11-14 \text { years })\end{array}$ & 0.40 and 0.46 \\
\hline Mathematics & 2 & A/B & $\begin{array}{l}7-9 \\
(11-14 \text { years })\end{array}$ & 0.41 and 0.86 \\
\hline Humanities & 1 & A/B & $\begin{array}{l}7-9 \\
(11-14 \text { years })\end{array}$ & 0.30 \\
\hline Technology studies & 1 & A/B/C** & $\begin{array}{l}11-12 \\
(16-18 \text { years })\end{array}$ & 0.14 \\
\hline Drama & 1 & A/B/C & $\begin{array}{l}11-12 \\
(16-18 \text { years })\end{array}$ & 0.61 \\
\hline Film, TV and Media & 1 & A/B/C & $\begin{array}{l}11-12 \\
(16-18 \text { years })\end{array}$ & 0.86 \\
\hline Visual art & 1 & A/B/C & $\begin{array}{l}11-12 \\
(16-18 \text { years })\end{array}$ & 0.34 \\
\hline Engineering & 1 & A/B/C & $\begin{array}{l}11-12 \\
(16-18 \text { years })\end{array}$ & 0.21 \\
\hline
\end{tabular}

Note $* \mathrm{~A} / \mathrm{B}$ : Traditional classroom (Baseline)/ILE (Intervention)

Note $* * \mathrm{~A} / \mathrm{B} / \mathrm{C}$ : Traditional classroom (Baseline)/ILE (Intervention 1)/ILE + Time (Intervention 2)

affected (but were not sure how, when and why) a discernible change in their practice when they occupied a different spatial layout, and this correlated to significant improvement in academic outcomes. On the other hand, some teachers' pedagogies and practices remained largely unaffected, and therefore the change in space had a minimal impact on academic results.

Blackmore et al. (2011), Gislason (2010) and Tanner (2008) found few studies that evaluated how the occupation of different learning environments influenced the nuances of teacher practice and the resulting impact on student learning. The earlier work of Byers et al., (2018b) is an example of an exception to this trend. It presented data through the quantitative analysis of repeated observations of a cohort of teachers prior to, on initial occupation, and then during longer-term inhabitation of an ILE. It described how teachers initially altered and further refined their practice to take advantage (or not) of the postulated affordances of an ILE, as well as documenting those instances of no such change. It further highlighted the mediating role of teacher spatial competency. Spatial competency explains how some teachers, due to their beliefs and pedagogical and discipline knowledge, were more able to articulate how, when and why their practice changed or remained the same when placed in a different physical learning environment (Lackney, 2008; Leighton, 2017; Steele, 1973). 


\section{The Context}

Since 2010, the site school has engaged in a strategic initiative to better understand the impact of different spaces on teaching and learning. Even though the school had engaged in an iterative process of low-cost refurbishments, the vast majority of classrooms were typical of traditional classrooms that Dovey and Fisher (2014) described as Type A spaces (Fig. 1).

As is illustrated in Fig. 2, all were conventional cellular spaces accessed by a corridor or veranda. The layout of chairs and desk were set in rows or groups facing the 'fireplace' teaching position at the front of the classroom (Reynard, 2009). Even though all Mathematics classes at the school were timetabled in Type A spaces, a significant proportion of the teachers within this sample participated in the earlier spatial interventions at the school. As a result, it was assumed that the spatial competency of the Mathematics sample was more developed than that of their peers.

The second group of spaces were cellular Science laboratories accessed by a substantial Learning Commons (Fig. 3). These spaces best match those spaces that Dovey and Fisher (2014) identified as Type B spaces. These laboratories had large, fixed benches focused upon the front demonstration/teaching position, similar to the Type A spaces. Additional fixed practical areas (standing height benches with gas
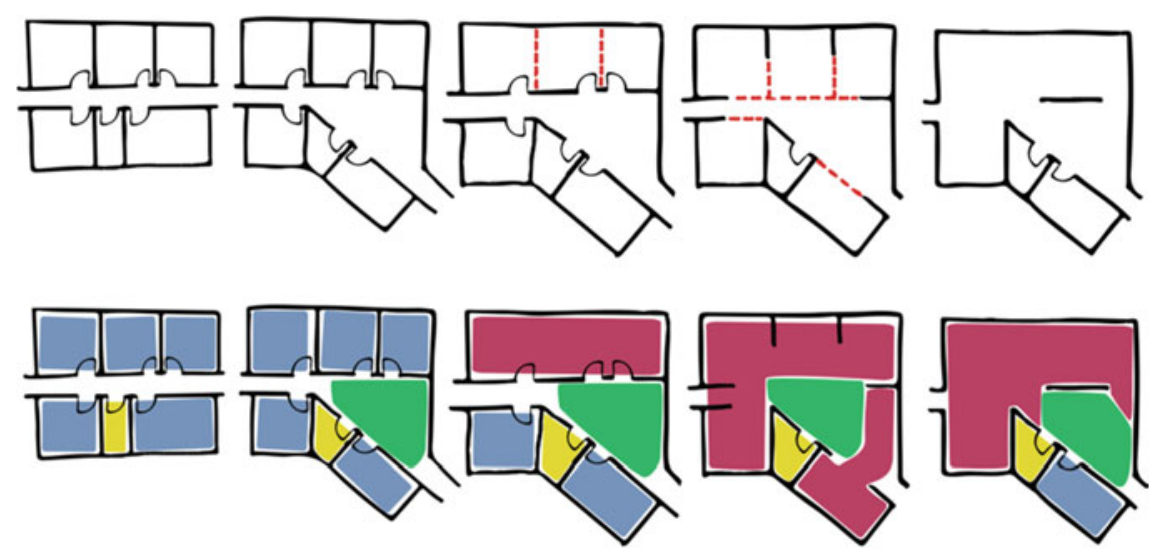

'A' 'B' 'C' 'D' ' $\mathrm{E}$ '

TRADITIONAL Learning spaces

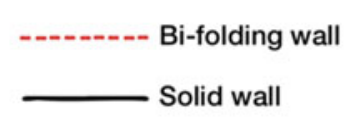

Solid wall

Store room

Classroom

Street-space

Commons

Fig. 1 Typology of spatial design (Source Imms, Mahat, Byers, \& Murphy (2017). Reprinted with permission from the ILETC Project) 


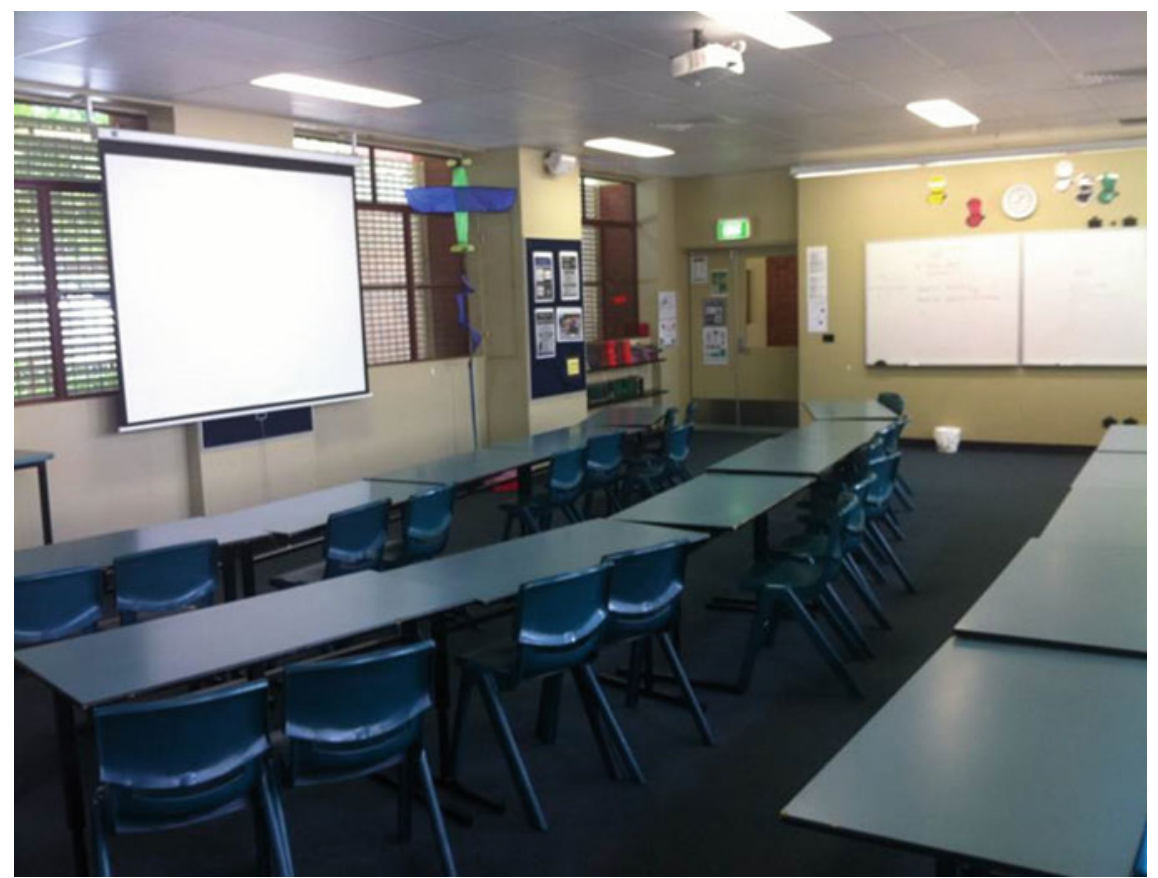

Fig. 2 Traditional classroom (Type A) mathematics classroom

and water) were situated around the periphery of each lab. However, they differed from other Type A spaces by a large exterior Learning Commons, which contained seating and large display areas.

The final spatial type evaluated in the study was the retrofitted Creative Precinct (Fig. 4). The Precinct merged two existing buildings into a single pedagogical space. The Precinct housed the Creative Arts (Drama, Film, TV and New Media, and Visual Art) and Design and Technology (Engineering and Technology Studies) Faculties. The open-studio design throughout, which best epitomises a Type D space, afforded the opportunity for teachers and students to occupy and transition between various external and internal spaces.

\section{Method}

Over a three-year period, more than 200 observations were conducted using the LPTS observational metric. However, this study, it will report on 91 observations across the subjects of Engineering, Mathematics and Science.

The macro-enabled Microsoft Excel LPTS metric, used by a trained observer, times student and teacher activity and produces a real-time visual breakdown across 


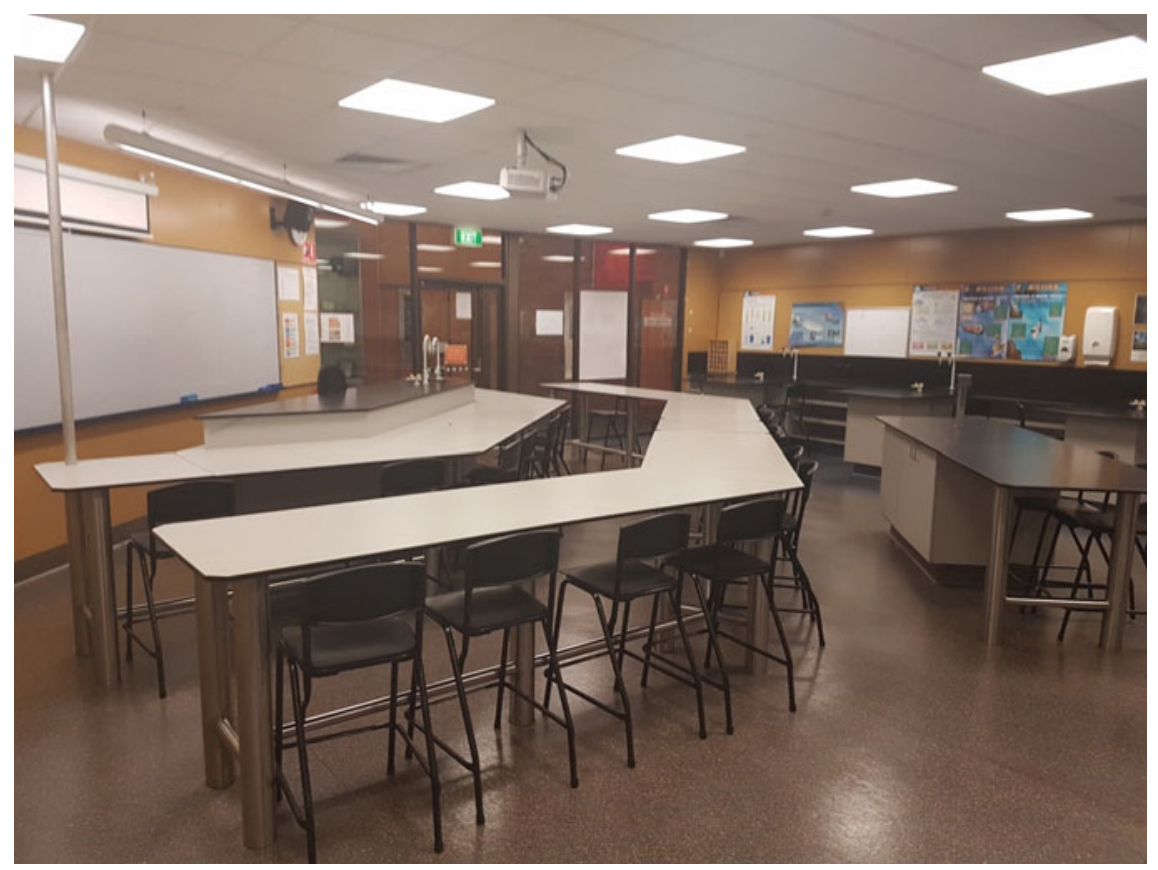

Fig. 3 Science laboratory (Type B)

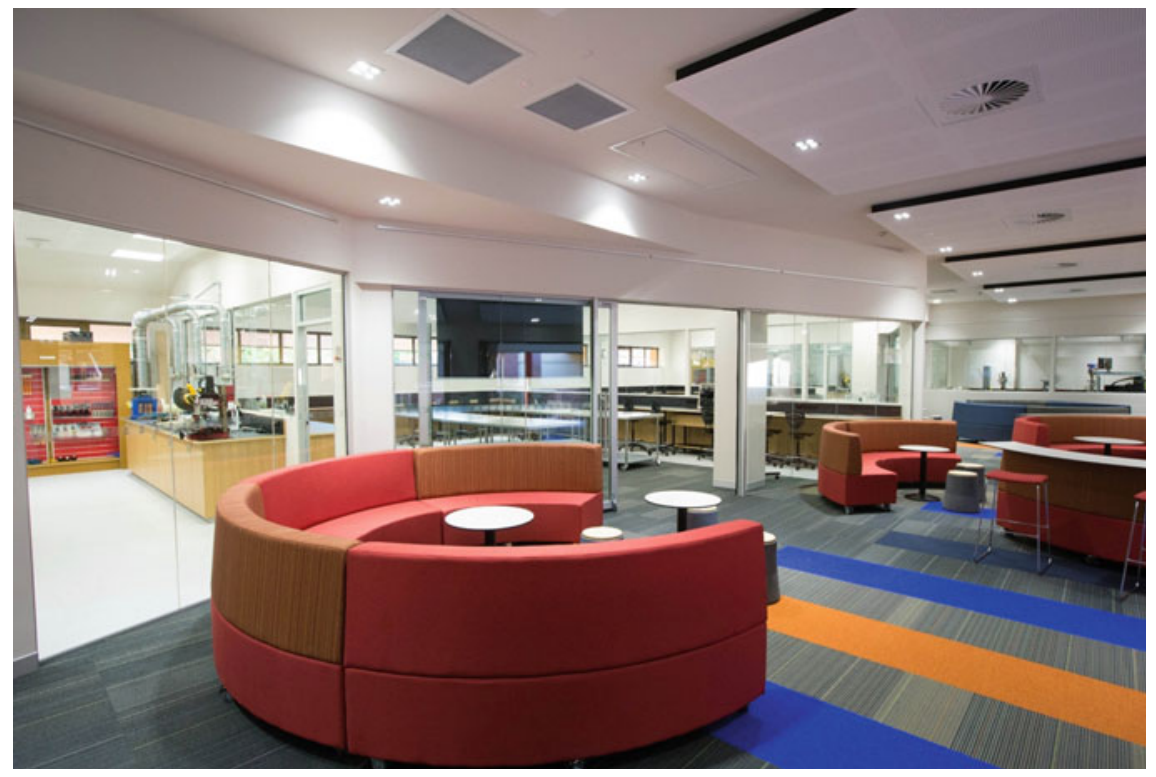

Fig. 4 Engineering space in the Creative Precinct (Type D) 
five domains (pedagogy, learning experiences, communities of learning, and student and teacher use of technology). The macro-enabled Microsoft Excel platform utilises a series of stopwatches to time student and teacher activity and behaviours across five domains (pedagogy, learning experiences, communities of learning, and student and teacher use of technology).

It can simultaneously log how long teachers engage in didactic instruction, such as a lecture, or when they encourage whole-class discussion, or question individuals or the entire class. This is done through a single observer interface. The interface allows a single observer to check the box that corresponds to an observed activity, which starts and then stops associated stopwatch timer. The macro-enabled programme then combines each observed instance of the activity, producing a cumulative time for each activity. The design of the metric produces an instantaneous visual breakdown for each observation that can then be easily shared with the teacher.

Pilot-testing during the earlier (Byers et al., 2018b) study demonstrated adequate interrater reliability, with Chi-square frequencies of the observations of six teachers by three observers across a total of twelve occasions not being statistically different $(p>0.05)$ (Bielefeldt, 2012). The use of time as the means to record activity, unlike traditional observational notes, also reduced the influence of observer inference. Furthermore, the application through a time-series design established controls of confounding variables (i.e. teaching and learning cycle and time of day) by the quasi-experimental design.

Repeated measures observational data for each participant (at a minimum of three observations) were completed by the same observer. The resulting data was averaged first, to produce a 'typical' lesson for that teacher. Next, the visual analysis identified general trends across the three spatial types. Multivariate visual and nonparametric analysis to identify statistically significant differences in activities and behaviour between teachers, subjects and spatial types, will be the subject of future publications.

\section{Results and Discussion}

\section{Teacher Behaviour and Pedagogies}

The pedagogy domain of the LPTS metric included the attributes of: didactic instruction, interactive instruction, facilitation, providing feedback, class discussion and questioning. The visual analysis identified notable pedagogical differences between the subjects that were considered to be somewhat 'conceptually similar' (Fig. 5). Typically, teachers in this sample displayed a pedagogical approach best aligned with a variant of teacher-guided (or fully guided) explicit instruction (see Kirschner, Sweller, \& Clark, 2006; Rosenshine, 1987). These subjects favour systematic and well-defined content, and procedural knowledge, which Rosenshine (1987, 2012) found is best (when compared to purely constructivist methods) taught through explicit instruction. Furthermore, explicit instruction bests support novices (students) 


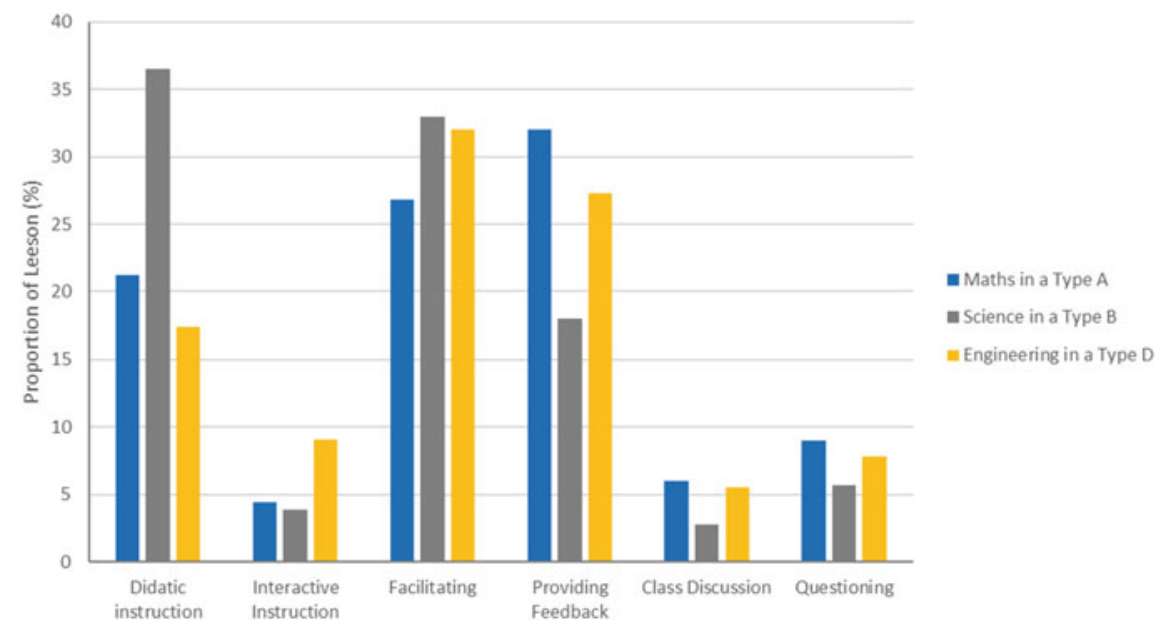

Fig. 5 Proportional breakdown of teacher pedagogies in mathematics in Type A $(n=31)$, science in Type $\mathrm{B}(n=29)$ and engineering in Type $\mathrm{D}(n=31)$ spaces

to acquire, consolidate and encode the requisite surface knowledge for deeper learning/thinking without overwhelming their working memory, or 'cognitive load' (Hattie \& Donoghue, 2016; Kirschner et al., 2006).

Instruction (Didactic/Interactive) was observed in the initial stages of most lessons. The Science teachers in Type B spaces, which were the most rigid (due to the fixed student and teacher benches), mostly instructed from the traditional front of the space, for approximately $40 \%$ of a lesson, utilising a teacher-centred modality (Fig. 5). Here the built pedagogy of these spaces made it easier for teachers to engage in teacher-led and didactic instruction (Reynard, 2009). The rigidity of the space made any other pedagogical approach virtually impossible. As a result, this presents a concrete example of how the built pedagogy of a space overtly dictated teacher pedagogical practice. The rigidity of the fixed setting actively restricted the ease for which teacher could easily switch to or engage in other modalities.

The Mathematics teachers in Type A spaces where furniture was not fixed as in Type B labs, spent considerably less time (approximately $15 \%$ of lesson duration) instructing from the front-of-room position. Even though the spaces had, by their design, a similarly built implied pedagogy to the Science labs, the incidence of the modality of instruction in Mathematics classes was like that of the Engineering sample (approximately $25 \%$ of lesson duration) in the Type D spaces. It is argued that the enhanced spatial competency of the Mathematics sample, developed in previous spatial interventions, somehow supported them to use the given spatial affordances adeptly. Such evidence does push against that the current narrative that traditional classrooms are more likely to support a teacher-led, didactic instruction model than an ILE. 
Even though their spatial types differed, the Engineering and Mathematics teachers modelled a pattern of explicit instruction (Rosenshine, 1987). However, the decrease in time spent in a direct instruction mode (approximately 15\% of lesson duration) correlated to a higher incidence of Discussion and Questioning. Often, these samples utilised more active and responsive modes to check for student understanding through scaffolded worked examples. These modes supported students to consolidate student understanding from which schemata for deeper learning are built (Hattie \& Donoghue, 2016), while reducing their cognitive load (Kirschner et al., 2006). Importantly, this occurred in a traditional and ILE space. As a consequence, one could argue that the ability to complement the necessity of the teacher-led, didactic instruction model with the enhanced responsiveness (i.e. checking for student understanding) class discussion and questioning (Rosenshine, 2012) is not mutually exclusive, nor, restricted to the type of spatial layout.

Following the more teacher-led phase, teachers typically transitioned to some form of applied practice facilitated through 'facilitation' and supported by 'feedback'. The Engineering and Mathematics samples were quite dynamic about the space during this phase of the lesson. Greater movement about the room moderated behaviour and supported the efficient provision of feedback to an individual or small group of students. On the other hand, the Science sample remained for considerable periods of time at the fixed front bench. At times, teachers moved about the periphery of the arranged student benches. However, the rigid and tight arrangement of benches appeared to inhibit student and teacher movement. When feedback occurred, teachers were often at a distance from the students asking for assistance. This limited the teachers' capacity to efficiently assess and monitor student progress, and it seemed to inhibit opportunities for systematic correction and feedback (Rosenshine, 2012).

\section{Learning Experiences}

The 'learning experiences' domain of the LPTS metric included the attributes: formative assessment, receive instruction, remember/recall, understand, apply, analyse, evaluate and creation/practical activity. Dovey and Fisher (2014) and Upitis (2004) suggest that a more conventional or traditional classroom space operates at the transmission end of the learning continuum (Receive Instruction and Remember/Recall). The visual analysis of the Type B sample (Fig. 7) would support this suggestion, with students engaged in activities associated with the receipt and recall of surface knowledge. The passive reception of instruction (approximately $43 \%$ of each lesson) through a teacher-centric modality of learning was the dominant learning modality (Fig. 6). Progression through the learning cycle was often linear or lock-step, limiting those opportunities for students to actively engage in the consolidation of surface knowledge and deep learning.

The visual analysis of the Engineering and Mathematics samples revealed a greater differentiation of and increase in total student activity when compared to the Science sample. Both achieved this by facilitating different activities within the learning cycle 


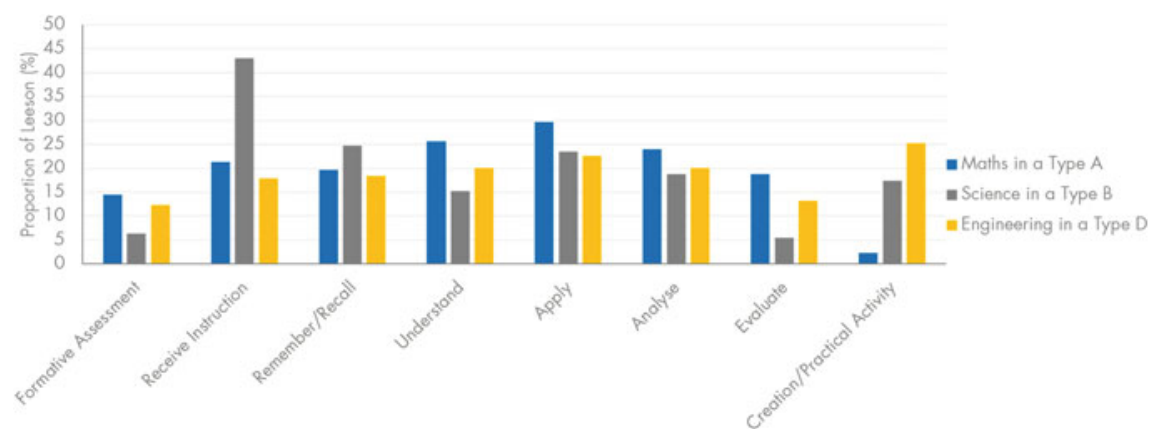

Fig. 6 Proportional breakdown of student learning experiences in mathematics in Type $\mathrm{A}(n=31)$, science in Type B $(n=29)$ and engineering in Type $\mathrm{D}(n=31)$ spaces

to occur concurrently, through a greater incidence of student-centric and informal learning modalities (Fig. 7). In particular, analysis of the Engineering sample demonstrates their utilisation of the full array spatial affordances, presented by their Type D layout. These teachers successfully utilised the design intent of the open-studio spaces to differentiate the modalities of learning and increased the incidence of practical activity. Not as pronounced, the Mathematics teachers were able to differentiate activities through the movement of students within the cellular space. Both samples actively exploited the available spatial affordances to orchestrate the full spectrum of learning experiences that supported the acquisition and consolidation of surface knowledge (Understanding) to the engagement with deeper learning (Apply, Analyse and Evaluate).

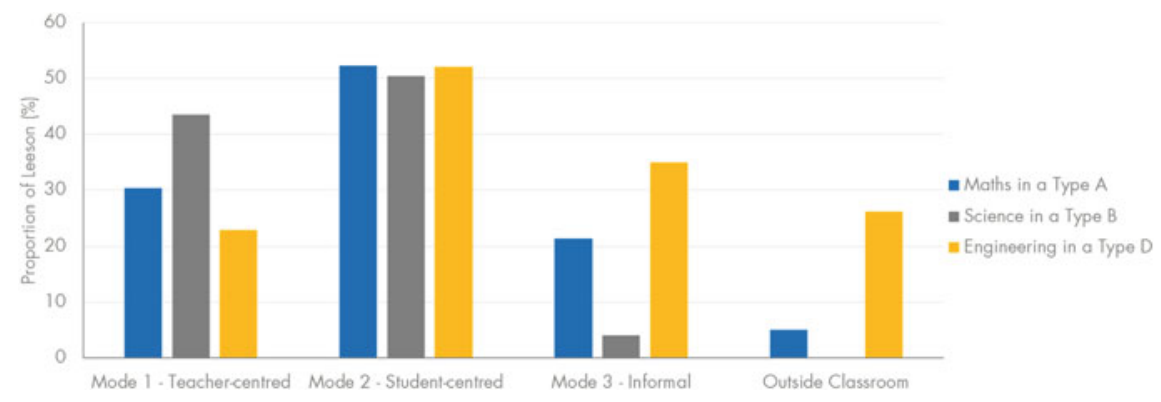

Fig. 7 Proportional breakdown of student occupation of the Fisher (2006) Modalities of learning in mathematics in Type A $(n=31)$, Science in Type $\mathrm{B}(n=29)$ and engineering in Type $\mathrm{D}(n=$ 31) spaces 


\section{Conclusion}

The current interest in learning environments is often driven by the premise that a change in space will act as a conduit for a desired pedagogical change. However, there exists a dearth of rigorous evaluative methods, thus empirical evidence, to show if the occupation of these different spaces manifests in this envisioned changed. This study attempted to illuminate how different spatial types, traditional (Types A and B) and ILE (Type D), affected both teacher and student activity and behaviour. The longitudinal observation of secondary Engineering, Mathematics and Science teachers through the LPTS observation metric presents initial empirical evidence through a novel evaluative approach.

The analysis found correlations that suggest the different spatial layouts did influence pedagogy, particularly in the comparison of Type B (Science) and Type D (Engineering) spaces. Importantly, it provides initial evidence (through the Mathematics sample) that a more developed spatial competency can allow teachers to utilise the 'limited' affordances (according to the current narrative) of a traditional classroom or Type A space, for pedagogical gain. Such evidence does work against a somewhat populistic, design-centric, narrative that is often espoused during learning space conversations. The data presented in this study suggest the so-called traditional classroom remains pedagogically sound under certain conditions, and greater emphasis needs to be placed on developing teacher spatial competency. This includes knowledge that helps teachers select the correct spatial design to match desired learning outcomes (Imms, 2018). Spatial competency, first coined by both Lackney (2008) and Steele (1973), and further developed by Leighton (2017), underpins a teachers' capacity to navigate and evolve their practices to utilise the affordances of the new spaces for pedagogical gain.

The comparative analysis of repeated observations of teachers from conceptually similar subjects in these three spatial types revealed two key findings. The first relates to how the different spatial types influenced the pedagogy and learning experiences. The analysis of the Science sample in a Type B layout suggested how its built pedagogy, a rigid layout about a teacher-centric, front-of-room orientation, contributed to the significant incidence of teacher-led and whole-class instruction. On the other hand, the observation of the Engineering teachers in the Type D layout revealed a different teaching and learning model. While these teachers still utilised teacherled and didactic instruction, it was shorter and refined in its intent. The analysis indicated the built pedagogy of the Type D space, somehow supported an increased prevalence of more active pedagogies working to a greater incidence of more independent learning experiences. It is a generalisation to say that Engineering and Science subjects are somewhat conceptual similar, however, it was clear that the different affordances presented by each spatial type influenced the differences in observed pedagogy and learning.

The second finding affirms the often-overlooked influence of teacher spatial competency. Even though both Lackney (2008) and Leighton (2017) focused on 
its theoretical development, this study does highlight its potential mediating influence, in a similar vein to that observed earlier studies at the site (Byers et al., 2014, 2018a). Early studies at this site, through analysis of teacher's voice, highlighted the differing perceptions in use, or not, of the affordances presented by different spatial types. The comparison between the Mathematics and Science teacher samples, in relatively similar spatial layouts, indicated how teachers with a more developed spatial competence can orchestrate different learning experiences. The Through use, the Mathematics sample appeared well attuned to the affordances of their traditional classroom, and how these could be used to facilitate responsive learning experiences, and increased levels of activity differentiation by students. Unlike the sequence of whole class linear progression of lessons observed in the Science classes, the Mathematics sample was more likely to create an environment that allowed students to progress from scaffolded (i.e. lower cognitions of remember/recall) through to deeper learning and thinking associated with the application of the learnt information to problems. Furthermore, the Mathematics teachers appeared more able to use the affordances of the given space to structure communities of learning, intertwined with class discussion and questioning, to scaffold this progression, despite the perceived restrictions of a traditional classroom.

These findings suggest that the LPTS observation metric, applied through a repeated measures approach, has the potential to inform evaluation of teaching and learning in different learning spaces. However, to improve the generality and validity of both the approach, the application of the LPTS metric and initial findings presented here, a longer-term evaluation of the impact of different subject types is required. Subsequent articles will focus on the more in-depth multivariate analysis of visual and nonparametric analysis to identify statistically significant changes in activities and behaviour between teachers, subjects, and spatial types.

Acknowledgements Data utilised in this research was obtained in adherence to the required ethical protocol of the author's host institution. All images and diagrams are the property of the author, or the author has obtained consent to use them from the appropriate copyright owner.

\section{References}

Benade, L. (2016). Is the classroom obsolete in the twenty-first century? Educational Philosophy and Theory, 1-12. https://doi.org/10.1080/00131857.2016.1269631.

Bielefeldt, T. (2012). Guidance for technology decisions from classroom observation. Journal of Research on Technology in Education, 44(3), 205-223. https://doi.org/10.1080/15391523.2012. 10782587.

Blackmore, J., Bateman, D., O'Mara, J., \& Loughlin, J. (2011). Research into the connection between built learning spaces and student outcomes: Literature review. Melbourne: Victorian Department of Education and Early Childhood Development. Retrieved from http://www.edu web.vic.gov.au/edulibrary/public/publ/research/publ/blackmore_learning_spaces.pdf.

Brooks, D. C. (2011). Space matters: The impact of formal learning environments on student learning. British Journal of Educational Technology, 42(5), 719-726. https://doi.org/10.1111/j. 1467-8535.2010.01098.x. 
Byers, T. (2017). Development of the linking pedagogy, technology and space observational metric. In B. Cleveland, H. Mitcheltree, \& W. Imms (Eds.), What's working? 2016: Informing education theory, design and practice through learning environmental evaluation (pp. 77-88). Melbourne: Learning Environments Applied Research Network.

Byers, T., Hartnell-Young, E., \& Imms, W. (2018). Empirical evaluation of different classroom spaces on student perceptions of the use and effectiveness of 1 to 1 technology British Journal of Educational Technology, 49(1), 153-164. https://doi.org/10.1111/bjet.12518.

Byers, T., \& Imms, W. (2014). Making the space for space: The effect of the classroom layout on teacher and student usage and perception of one-to-one technology. Paper presented at the 26th Australian Computers in Education Conference, Adelaide.

Byers, T., \& Imms, W. (2016). Evaluating the change in space in a technology-enabled primary years setting. In K. Fisher (Ed.), The translation design of schools: An evidence based approach to aligning pedagogy and learning environment design (pp. 215-236). The Netherlands: Sense.

Byers, T., Imms, W., \& Hartnell-Young, E. (2014). Making the case for space: The effect of learning spaces on teaching and learning. Curriculum and Teaching, 29(1), 5-19. https://doi.org/10.7459/ $\mathrm{ct} / 29.1 .02$.

Byers, T., Imms, W., \& Hartnell-Young, E. (2018a). Comparative analysis of the impact of traditional versus innovative learning environment on student attitudes and learning outcomes. Studies in Educational Evaluation, 58, 167-177. https://doi.org/10.1016/j.stueduc.2018.07.003.

Byers, T., Imms, W., \& Hartnell-Young, E. (2018b). Evaluating teacher and student spatial transition from a traditional classroom to an innovative learning environment. Studies in Educational Evaluation, 58, 156-166. https://doi.org/10.1016/j.stueduc.2018.07.004.

Byers, T., Imms, W., Mahat, M., Liu, K., \& Knock, A. (2018). A systematic review of the effects of learning environments on student learning outcomes. Innovative Learning Environments and Teachers Change. https://doi.org/10.13140/RG.2.2.23918.10561.

Dovey, K., \& Fisher, K. (2014). Designing for adaptation: The school as socio-spatial assemblage. The Journal of Architecture, 19(1), 43-63. https://doi.org/10.1080/13602365.2014.882376.

Fisher, K. D. (2006). The new learning environment: Hybrid designs for hybrid learning. Retrieved from Melbourne: http://www.woodsbagot.com/en/Documents/Public_Research/PUB LIC2\%20The\%20New\%20Learning\%20Environment.pdf.

Gislason, N. (2010). Architectural design and the learning environment: A framework for school design research. Learning Environments Research, 13(2), 127-145. https://doi.org/10.1007/s10 984-010-9071-x.

Hattie, J. A. C., \& Donoghue, G. M. (2016). Learning strategies: A synthesis and conceptual model. Science of Learning, 1, 1-13. https://doi.org/10.1038/npjscilearn.2016.13.

Imms, W., \& Byers, T. (2016). Impact of classroom design on teacher pedagogy and student engagement and performance in mathematics. Learning Environments Research, 19(2), 1-14. https:// doi.org/10.1007/s10984-016-9210-0.

Imms, W., Mahat, M., Byers, T., \& Murphy, D. (2017). Type and use of innovative learning environments in Australasian schools. ILETC Survey No. 1. Melbourne, Australia: University of Melbourne, LeARN. Retrieved from http://www.iletc.com.au/publications/reports.

Kirschner, P. A., Sweller, J., \& Clark, R. E. (2006). Why minimal guidance during instruction does not work: An analysis of the failure of constructivist, discovery, problem-based, experiential, and inquiry-based teaching. Educational Psychologist, 41(2), 75-86. https://doi.org/10.1207/s15326 985ep4102_1.

Lackney, J. A. (2008). Teacher environmental competence in elementary school environments. Children, Youth and Environments, 18(2), 133-159. www.colorado.edu/journals/cye.

Leighton, V. (2017). Teaching Space: Does a teacher's spatial competency affect their teaching and effect the different types of learning that takes place in a classroom? Paper presented at the Transitions Australasia: What is needed to help teachers better utilize space as one of their pedagogic tools, Melbourne.

Monahan, T. (2002). Flexible space \& built pedagogy: Emerging IT embodiments. Inventio, 4(1), 1-19. http://www.torinmonahan.com/papers/Inventio.html. 
Mulcahy, D., Cleveland, B. W., \& Aberton, H. (2015). Learning spaces and pedagogic change: Envisioned, enacted and experienced. Pedagogy, Culture \& Society, 23(4), 1-21. https://doi.org/ $10.1080 / 14681366.2015 .1055128$.

Oblinger, D. G. (2006). Space as a change agent. In D. G. Oblinger (Ed.), Learning spaces (pp. 1.11.4). EDUCAUSE.

OECD. (2013). Innovative learning environments. Paris: Organisation for Economic Cooperation and Development.

Painter, S., Fournier, J., Grape, C., Grummon, P., Morelli, J., Whitmer, S., et al. (2013). Research on learning space design: Present state, future directions. Ann Arbor: Society for College and University Planning.

Reynard, R. (2009). Designing learning spaces for instruction, not control. Campus Technology. Retrieved from http://campustechnology.com/articles/2009/04/29/designing-learningspaces-for-instruction-not-control.aspx.

Rosenshine, B. (1987). Synthesis of research on explicit teaching. In R. E. Bruce \& E. E. Grimsely (Eds.), Reading in educational supervision (Vol. 2, pp. 145-153). Alexandria, VA: Assocation for Supervision and Curriculum Development.

Rosenshine, B. (2012). Principles of instruction: Research-based strategies that all teachers should know. American Educator, 36(1), 12-19, 39.

Steele, F. I. (1973). Physical settings and organization development. Reading: Addison-Wesiey.

Tanner, C. K. (2008). Explaining relationships among student outcomes and the school's physical environment. Journal of Advanced Academics, 19(3), 444-471.

Upitis, R. (2004). School architecture and complexity. Complicity: An International Journal of Complexity \& Education, 1(1), 19-38. www.complexityandeducation.ca.

Imms, W. (2018). Innovative learning spaces: Catalysts/agents for change, or 'just another fad'? In S. Alterator \& C. Deed (Eds.), School space and its occupation: The conceptualisation and evaluation of new generation learning spaces (pp. 107-118). Amsterdam, The Netherlands: Sense Publishing.

Terry Byers (Australia) currently works the Anglican Church Grammar School, as the Director of the Centenary Library and Innovation in Learning. He is an Adjunct Associate Professor in the School of Education (University of Queensland) and does research on Pedagogic Theory, Educational Technology and Curriculum Theory. He is currently involved in research projects that evaluate the impact of the 'Spatial Transition from Conventional to Innovative Learning Environments on Teachers', 'Affordances of Digital Technology' and 'Making Effective Learning Strategies Stick'.

Open Access This chapter is licensed under the terms of the Creative Commons Attribution 4.0 International License (http://creativecommons.org/licenses/by/4.0/), which permits use, sharing, adaptation, distribution and reproduction in any medium or format, as long as you give appropriate credit to the original author(s) and the source, provide a link to the Creative Commons license and indicate if changes were made.

The images or other third party material in this chapter are included in the chapter's Creative Commons license, unless indicated otherwise in a credit line to the material. If material is not included in the chapter's Creative Commons license and your intended use is not permitted by statutory regulation or exceeds the permitted use, you will need to obtain permission directly from the copyright holder.

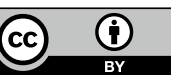

